\title{
Translation and Culture: Translating Idioms between English and Chinese from a Cultural Perspective
}

\author{
Dayan Liu \\ School of Foreign Languages, Chongqing Jiaotong University, No.66, Xuefu Road, Nan'an District, Chongqing, China \\ Email: lucyldy2008@hotmail.com
}

\begin{abstract}
Translation is not only an interlingual communication, but a cross-cultural transfer, which involves a comparative study of the SL culture and TL culture. In translating cultural specificities, especially idioms, two criteria are proposed, informativeness and effectiveness, by which three translation methods are thus suggested: 1) literal translation; 2) literal translation with footnotes or explanatory phrases; 3) equivalent or corresponding TL idioms. A skillful use of those methods, subject to different contexts and purposes, serves to promote cultural exchange between English and Chinese. This contribution, in turn, aims to usher in further in-depth study of relations between culture and translation.
\end{abstract}

Index Terms - culture, translation, idioms, informativeness, effectiveness

\section{Language, Culture and Translation}

Translation has traditionally been perceived as an interlingual communication, whereas some translation theorists, like Hans J. Vermeer, are vigorously against the conception of translation as simply a matter of language but view translation primarily as a cross-cultural transfer or intercultural communication (Bassnett \& Lefevere, 1990).

The probe into this type of intercultural communication is first beset by a major problem caused by the disagreement over the ambiguous and intriguing concept of culture. The definitions of culture amount to over 200, each from its own perspective. The classic definition is presented by Edward Burnett Tylor (1920), father of cultural anthropology:

Culture, or civilization, taken in its broad, ethnographic sense, is that complex whole which includes knowledge, belief, art, morals, law, custom, and any other capabilities and habits acquired by man as a member of society. (p.1)

It is an all-inclusive definition, one of his most widely recognized contributions to anthropology and the study of religion.

Some definitions of culture have a direct bearing on translation. Ward H. Goodenough, an American ethnologist, maintains that culture is the forms of things that people have in mind, their models for perceiving, relating, and otherwise interpreting them (Nord, 1997). It has served as a general starting point for functionalist approaches to translation, first introduced into the study of cross-cultural communication and slightly modified by Göhring. On the basis of Göhring's perception, Vermeer accentuates the following features of culture:

a) dynamic qualities, focusing on human action and behavior;

b) comprehensiveness, regarding culture as a complex system determining any human action or behavior, including language; and

c) the possibility of it being used as a starting point for a descriptive and explicative or prescriptive approach to culture-specificity. (ibid)

Views of culture may differ, but some common grounds can still be found: translation theorists or linguists all agree upon the close link between language and culture. Vermeer sees language as an intrinsic part of culture, whose view is shared by Mary Snell-Hornby particularly when culture is defined as "a totality of knowledge, proficiency and perception" (Nord, 1997, p.23). John Lyons (1968), an English linguist, too, considers the language of a particular society as an integral part of its culture, who holds that the lexical distinctions drawn by each language will tend to reflect the culturally-important features of objects, institutions and activities in the society in which the language operates. Equally aware of the inseparability of language and culture, Nida (1993) believes that since culture is generalized as "the totality of beliefs and practices of a society", nothing is more strategically significant than the language through which its beliefs are expressed and conveyed and by which most interaction of its members happens (p.105). Slightly different is how Peter Newmark (1988) perceives language and culture, who does not, operationally, think of language as a component of features of culture, but refers culture to the way of life and its manifestations characteristic of a community that uses a particular language as its means of expression. No matter whether those theorists regard language as part of culture or not, they all acknowledge that language and culture are closely connected or interdependent. It is, therefore, not surprising that language and culture are sometimes spoken of as "languaculture" —a single entity (Nord, 1997, p.25). 
Since language and culture are interrelated, and translation is conceived of as an interlingual communication as well as a process of cultural transfer, translators are almost always required to be both bilingually and biculturally competent. For truly expert translating, biculturalism matters even more than bilingualism, as words only have meanings in terms of the culture in which they operate, and the understanding of the source-language text is influenced and conditioned by the culture. On the other hand, the translator, as a special type of reader and an insider of his own culture, cannot always be a passkey to opening all the cultural locks. He cannot completely transcend the boundaries of his own cultural heritage into the world of the other. He himself, sometimes, may be too locked into his own cultural way of thinking to be able to share other cultures. Hence, the degree of difficulty and the quality of translation have more to do with culture than with language itself.

\section{A COMPARATIVE STUdy OF CULTURES InVOLVED In TRANSLATION}

The translator's knowledge of the cultures concerned is based, consciously or unconsciously, on a comparative study of them. In other words, translating means comparing cultures. This comparison indicates that the translator interprets source-culture phenomena in the light of his own culture-specific knowledge of that culture, from either the inside or the outside, dependent upon the direction of translation, whether from or into the translator's native language-and-culture. The concepts of one's own culture will thus be used as the touchstones for the perception of otherness. Comparing cultures embraces both cultural similarities and differences.

As anthropologists note, cultural similarities, like the recognition of reciprocity and equity in inter-personal relation, the response to human kindness and love, the desire for meaning in life, which unite different peoples in a common humanity, far outweigh cultural differences that divide people into distinct groups. Thanks to the similarities in mental process, somatic responses, range of cultural experience and capacity of adjustment to the behavior patterns of others, a high degree of effective communication is possible among all people. Most important is the fact that all people tend to reason in much the same way. In a discourse, for instance, the ordering of elements may vary considerably, but the underlying logic of consequential relations is amazingly similar. Despite the existence of differences, one is able to imagine how other people organize their thoughts and reason, and how the people of another language-culture may rightly differ in their behavior and values. Those elements that can help the translator cross the cultural frontiers are what Wilss terms "universals" (Gentzler, 1993, p.58). It is just those cultural universals that provide a basis for mutual understanding, which, in turn, makes translation and cultural exchange at all possible.

However, one cannot face fairly the translator's problems without reckoning with the many and sometimes striking differences between cultures, since cultural diversities or cultural conflicts are, after all, the major reasons for the breakdown of cross-cultural communication. Cultural differences have a direct bearing on the problems of understanding and expression encountered in translation. Everything observed as being different from our own culture is specific to the other culture, whereas cultural difference, whether between language-pairs that are culturally closely related or those with only distant cultural connections, is one of degree and not of kind (Bassnett \& Lefevere, 1990). The divide between Chinese culture and western culture ranks quite high with the greatest number of cultural factors subject to variation and the least commonality.

Exploring cultural differences requires a valid and more general classification of culture as the specific cultural phenomena are too numerous to be accounted for. However, the ways to categorize are no less varied than the definitions of culture. In a broad sense, culture is subdivided into paraculture (the norms, rules and conventions valid for an entire society), diaculture (norms, rules and conventions valid for a particular group within the society, such as a club, a firm, or a regional entity) and idioculture (the culture of an individual person as opposed to other individuals) (Nord, 1997). In a restricted sense, Newmark and Nida classify it into five groups: ecology, material, social, religious and linguistic culture. This paper prefers to group culture into historical, geographical, customary and religious perspectives. An example from the perspective of historical culture is cited in the following to show the cultural differences between Chinese and English:

Historical culture evolves with a particular historical development. It is the product of social heritage and differs with histories. Some idioms with reference to a particular historical figure pose a challenge to translation. For instance, if the Chinese idiom “东施效蘋” is rendered literally into English, unaware of the cultural connotations, as “Dong Shi imitates a frown" or "Dong Shi imitates Xi Shi", westerners will definitely feel at a loss about who Dong Shi and Xi Shi are, or what this phrase means. This idiom comes from a Chinese historical story, in which Xi Shi (西施) was a beauty during the end of Spring and Autumn Period in the ancient State of Yue, who often frowned exhibiting sexualized frailty and suffering, whereas Dong Shi (东施), the exact opposite of Xi Shi in being extremely ugly, emphasized her own ugliness while imitating Xi Shi's frown. The idiom has taken on a meaning to signify one's vain attempt imitating another only to emphasize one's own weaknesses. With the specific cultural connotation considered, “东施效頻” is better rendered as "Ugly Dong Shi blindly imitates beautiful Xi Shi's frown with ludicrous effect" to make it meaningful.

\section{Methods of Translating CUltural Specificities}

In light of the vast and striking differences between Chinese and western cultures, the difficulty encountered in 
translating can be fairly understood, especially in translating texts with distinctive cultural features or culture-specific conventions. In translating such texts, usually there are two opposite approaches: to translate literally in a bid to convey the maximum cultural messages or to adapt to the target-culture in order to evoke the greatest effect. Practically, neither is all-powerful under any circumstance. Literal translation, if used in improper situations, will throw the reader into an abyss of bewilderment and, as a result, fail the purpose of translation. The nationalization of a foreign culture in the interest of the reader, on the other hand, provides only momentary gratification at the cost of concealing cultural differences and disparities and eliminating cultural consciousness caused by different cultural backgrounds. Further, they either overestimate or underestimate the reader's acceptability.

As an intercultural communication, translation aims at translating culture, bridging the two worlds of source-language (SL) author and the target language (TL) reader, and the two cultural domains. To translate is to seek the highest possible degree of cultural exchange through the translator's tough work of comparing, introducing, absorbing, etc. Based on this revelation, two translation criteria should therefore be noted: informativeness and effectiveness, which make up the degree of cultural exchange. To put it plainly, the more cultural messages of a SL text are transferred to the TL text, the more informative the cultural exchange, particularly where there are vast differences, and the more tactfully the cultural messages are expressed, the more effective the cultural exchange. It is favourable to attain an equilibrium between the two, but sometimes this task is hard indeed. When there is a conflict, informativeness usually takes priority, with a moderate degree of effectiveness, to convey as much cultural information as possible and fulfill the purpose of cultural exchange. This approach will be applied to the translation of idioms between English and Chinese.

\section{TRANSLATING IDIOMS}

Idioms are combinations of words whose meanings cannot be deduced from the meanings of the individual parts. They are heavily culturally-loaded phrases or sentences, usually highly specialized in meaning and closely tied to distinctive cultural features and attitudes. Idioms belong to figurative language, in which cultural differences are often mirrored and from which translation problems often arise. Here the term "idiom" is used in its broad sense, encompassing phrase, clause and sentence idioms (proverbs and sayings). In translating idioms, by the criteria of informativeness and effectiveness, three methods are recommended:

a) literal translation

b) literal translation with footnotes or explanatory phrases

c) equivalent or corresponding TL idioms

Note that those methods of translating idioms should be used in proper situations, subject to certain restrictions respectively, and that different ways of translation are rarely cases of "right" versus "wrong", but of appropriateness. In the following, those methods are explained and exemplified, with their restrictions specified, in an effort to strike a balance between informativeness and effectiveness in idiom translation.

\section{A. Literal Translation}

Some translation theorists like Nida have stated that figurative expressions, including idioms, can rarely be translated literally, but for the sake of cultural transfer and informativeness, literal translation can be applied on the condition that effectiveness is achieved to certain degree. For instance, "A cat has nine lives" is appropriately rendered into Chinese as “猫有九条命”, the literal translation of which not only conveys the same figurative meaning that one has a good chance of surviving harsh conditions, but also retains the original image of "cat" (猫) as well. Though the English idiom is rooted in western culture, it is well understood and accepted by Chinese readers. Therefore, as long as the translated idioms pose few problems to TL readers, literal translation is a good way to promote cultural exchange. This method is often used in the following situations to maintain its advantages:

1. when the SL idiom's figurative meaning is conveyed by the form and self-evident

(1) (SL) 不入虎穴焉得虎子?

(TL) How can one obtain tiger cubs without entering the tiger's lair?

(SL) Blood is thicker than water.

(TL) 血浓于水

In example (1), the literal translation conveys the figurative meaning of "how can one gain without taking any risk", since it is evident that it takes great risk to enter the tiger's lair. Besides, the images of tiger cubs (虎子)and the tiger's lair (虎穴) are understood and accepted in both cultures. In example (2), the meaning of the literally translated Chinese idiom “血浓于水” is self-evident that the bonds of family and common ancestry are stronger than those bonds between unrelated people (such as friendship). Similarly, the images of blood (血) and water (水) are retained in the target culture, evoking the same effect.

2. when the SL idiom is used in either its literal sense or figurative sense, or both, to make a pun or achieve some other special purposes

(3) (SL) "Oh! Tell us about her, Auntie," cried Imogen, "I can't just remember her.

She is the skeleton in the family cupboard, isn't she? ..." 
“She wasn't much a skeleton as I remember her," murmured Euphemia,

"extremely well covered."

(TL)“哦！请给我们讲讲她的事儿吧, 好姑妈, ”伊莫金喊道: “我简直不记得她了, 她是我们家衣柜里的骷髅, 见不得人, 是吗? ......”

“我记得她并不像是骷髅, ”尤菲米娅低声说, “肌肉顶丰满呢。”

Example (3) illustrates a special usage of the idiom "a skeleton in the cupboard", whose figurative sense of "a shame in the family” (见不得人) is used by the first speaker while whose literal sense of “a very thin person” (骷髅) is used by the second speaker. Thus, a literal translation is adopted, keeping the image of a "skeleton" (骷髅), to make the communication meaningful and effective.

Literal translation of idioms has great advantages in terms of cultural exchange by keeping the images, but there are still many cases in which simple literal translation may cause misunderstanding or incomprehensibility, and as a result, reduce the effectiveness of communication. In such cases, the translator should resort to other methods.

\section{B. Literal Translation with Footnotes or Explanatory Phrases}

In order to convey the most possible cultural information of the SL idiom effectively, the image and the figurative meaning should both be transferred to the TL text. When literal translation fails to fulfill this task, some supplementary measures are employed, such as footnotes or explanatory phrases. The explanation can be added in the form of a supplementary part following a dash, a coordinate part, the logical predicate of the literal translation or even another sentence. It usually functions in the following ways:

1. to decipher the figurative meaning of the SL idiom

(4) (SL) Achilles' heel

(TL) 阿基里斯的脚后跟一一唯一弱点

In example (4), if translated literally alone, the idiom “Achilles' heel”(阿基里斯的脚后跟) makes no sense to Chinese readers though the image of Achilles, a great warrior in the Trojan War, is retained. To remedy this deficiency, the explanatory phrase “唯一弱点” (the only deadly weakness) is added to make clear its figurative meaning while keeping the cultural image.

2. to explain the cultural background or characteristics of the image used in the SL idiom

(5) (SL) 三个臭皮匠, 合成一个诸葛亮。

(TL) Three cobblers with their wits combined would equal Zhuge Liang the mastermind.

Case (5) outlines the cultural characteristics of the image in the SL idiom Zhuge Liang (诸葛亮), who was a chancellor of the state of Shu Han during the Three Kingdoms period of Chinese history and is often recognized as the wisest individual in China. Thus, his name Zhuge Liang is followed by an appositive "the mastermind" to render this information explicit.

3. to translate the omitted part and implied sense, or to indicate the undertone

Some SL idioms are often shortened into simplified forms without changing their figurative meanings at all, e.g. Jack of all trades, which is the shortened form of Jack of all trades and master of none. To the TL reader, the literal translation of most shortened forms of the SL idioms cannot carry as many cultural messages as they do to the SL reader.

(6) (SL) It is the old story of the stitch in time.

(TL) 还是那句老话: 及时缝一针, 可以省九针。

In case (6), "the stitch in time" is the shortened form of "a stitch in time saves nine", which means if you sort out a problem immediately it may save a lot of extra work later. To make the literal translation meaningful and the image intact, the omitted part “saves nine” (可以省九针) is supplemented in the translation.

This method serves to strength the advantages of literal translation while increasing its effectiveness. However, footnotes or explanatory phrases may seem quite wordy and cause some pragmatic problems, like the lack of space. In light of the disadvantages, replacing the SL idiom with an equivalent or corresponding TL idiom can be a simpler option.

\section{Equivalent or Corresponding TL Idioms}

Using an equivalent or corresponding TL idiom to replace the SL idiom can render explicit the figurative meaning and transfer effectively the cultural messages, but this method should be used on the premise that the SL idiom and the corresponding TL idiom are really equivalent in meaning, style, colouring, etc. But sometimes this approach risks sacrificing the original cultural images. Employing an equivalent TL idiom has another benefit that both the SL and TL idioms enjoy an approximately equivalent level of idiomatic speech, so that one does not seem more scholarly or more stilted than the other. It is advisable that this method be applied in the following situations:

1. with the same figurative meaning and a similar image

(7) (SL) to add fuel to the flame

(TL) 火上加油

(SL) to fish in troubled waters 


\section{(TL) 混水摸鱼}

(SL) a drop in the ocean

(TL) 沧海一粟

Examples (7) to (9) have the same figurative meanings and the same or similar images, for instance, flame (火) and fuel (油) in (7), troubled waters (混水) and fish (鱼) in (8), ocean (沧海) and drop (粟) in (9). They are equivalent in style and colouring, and highly effective in transferring most of the cultural messages carried by the SL idioms.

2. with the same figurative meaning but without any images in both SL and the TL idioms, or with images in the TL idiom but not loaded with strong national colouring

(10) (SL) at one's wit's end

(TL) 智穷才尽

(11) (SL) 少年老成

(TL) to have an old head on young shoulders

Case (10) enjoys the same figurative meaning with no images in both SL and the TL idioms while case (11) has the images of "head" and "shoulders" in the TL idiom, which are not present in the SL idiom.

3. with the same figurative meaning but different images

(12) (SL) 血流如注

(TL) to bleed like a pig

(13) (SL) 一贫如洗

(TL) as poor as a church mouse

In those examples above, the images differ, with pig for “注”(spout) in (12) and a church mouse for “洗” (washed) in (13). As this method invariably results in a loss of cultural information, it is recommended only when a literal translation cannot provide a comprehensible TL text and the addition of footnotes or explanatory phrases may create a too wordy text.

This method of employing an equivalent or corresponding TL idiom should be used with great care on the premise that both SL and TL idioms have the same figurative meaning. But some seeming equivalents are actually different. They are termed "false friends", which refer to "SL and TL items which have the same or very similar form but different meanings, and which consequently give rise to difficulties in translation (and indeed interlingual communication in general)" (Shuttleworth \& Cowie, 2004, pp.57-58). For instance, the English idiom "hair stands on end” and the Chinese “equivalent” “怒发冲冠” are similar in form but they are in fact false friends since the former indicates "fear" or "terror" while the latter suggests "anger". In idiom translation, once we encounter a happy equivalent with a similar form we should be on our guard. Similar examples are:

\begin{tabular}{|l|l|l|l|}
\hline English idioms & meaning & False friends in Chinese & meaning \\
\hline (14) pull one's leg & to joke & 拉后腿 & to hold someone back \\
\hline (15) eat one's words & to admit one's mistake & 食言 & to break one's promise \\
\hline (16) a walking skeleton & a skinny person & 行尸走肉 & a boring or unenterprising person \\
\hline
\end{tabular}

In addition, we should be cautious of some corresponding idioms that differ in cultural background and national colouring. If “班门弄斧” is replaced by a corresponding idiom “teach one’s grandmother to suck eggs”, it gives rise to a cultural loss, as the Chinese idiom embodies an important cultural message that Lu Ban (班) was a well-known Chinese carpenter, engineer and inventor during the Spring and Autumn Period. Therefore, to preserve the cultural information, it is desirable to render it as "showing off one's proficiency with the axe before Lu Ban the master carpenter". In short, the validity to naturalize translation is appraised on the condition of not hampering the "foreignness" of the source text to avoid cultural distortion or even loss.

\section{Other Methods}

In addition to the methods discussed, a combination of them in dealing with a single problem is suggested as well, similar to the method of "couplets" proposed by Newmark (1988, p.91). It is like "two or more bites at one cherry". Mention should also be made of free translation, which should be treated as the last resort because it often greatly reduces the informativeness of the cultural messages although it is necessary in some cases for the effectiveness of communication. To sum up, in translating idioms as well as other culture-bound terms and phenomena, those methods should not be rigidly followed but subject to different contexts and purposes. A skillful use of them serves to promote cultural exchange and widen the readers' vision, which, in turn, paves the way for further cultural exchange.

\section{CONCLUSION}

The study of the effects that culture has on translation may help to disclose the aspects of translation that the literarily-based and linguistically-based translation theories have failed to do. Without a systematic study of translation and culture, any so-claimed theoretical system of translation studies is incomplete. This contribution focuses on the handling of idioms and will shed light on the translation of other cultural specificities. It is intended to usher in further 
in-depth study of relations between culture and translation.

\section{REFERENCES}

[1] Bassnett, Susan \& André Lefevere, eds. (1990). Translation, History and Culture. London: Casell.

[2] Gentzler, Edwin. (1993). Contemporary Translation Theories. London: Routledge.

[3] Lyons, John. (1968). Semantics. Cambridge: Cambridge University Press.

[4] Newmark, Peter. (1988). A Textbook of Translation. New York: Prentice-Hall International.

[5] Nida, E.A. (1993). Language, Culture and Translating. Shanghai: Shanghai Foreign Language Education Press.

[6] Nord, Christiane. (1997). Translation as a Purposeful Activity: Functionalist Approaches Explained. Manchester: St. Jerome.

[7] Shuttleworth, Mark \& Moira Cowie. (2004). Dictionary of Translation Studies. Shanghai: Shanghai Foreign Language Education Press.

[8] Tylor, Edward. (1920/1871). Primitive Culture. New York: J.P. Putnam’s Sons.

Dayan Liu earned her MA in Translation Theory and Practice from Sichuan International Studies University, China, in 2000. She is currently an Associate Professor at the School of Foreign Languages, Chongqing Jiaotong University, Chongqing, China. Her research interests cover Translation Studies, Cultural Studies, intercultural communication, Teaching English to Speakers of Other Languages, Second Language Acquisition, teacher training and education, etc. 